\title{
A CONTROVÉRSIA SOBRE A EXPERIÊNCIA PRIVADA NA MODERNIDADE
}

\author{
Res. por Yedro Eduardo Portilho de Nader
}

O trabalho de Richard Sennett sobre $O$ declínio do Homem Público ${ }^{1}$ apresenta como um obstáculo a relevância excessiva que a experiência íntima tem no mundo moderno.

Nas recentes eleições brasileiras uma impressão global percorre o campo social: a de que os debates feitos pelos candidatos dão-se prioritariamente em torno da vida pessoal e das virtudes privadas de cada um. A conclusão a que se chega é de que o voto é dado conforme as qualidades particulares e a personalidade do candidato e não segundo o programa que ele defende.

Esta impressão é extensível, em grau diferente, a todo o panorama eleitoral moderno. Nào é preciso muito esforço para acompanhar nos noticiários e perceber como nos países de maior projeção as eleições e a política profissional de maneira geral, são pautadas pela "espetacularização da personalidade ${ }^{n 2}$.

O livro de Sennett discute esta vocação das eleições contemporâneas, inserindo-a numa tendência mais ampla do mundo moderno; a conversão da importância do domínio público e das matérias impessoais no privilégio da vida privada e dos termos pessoais. Os indivíduos na modernidade, explica o autor, sentem-se decepcionados com o mundo exterior, que lhes parece rançoso e vazio, e voltam-se ansiosos para o mundo interior, a sua intimidade e emoções pessoais, ao aconchego do lar. O comportamento eleitoral é o ponto terminal desta tendência.

1 Sennett, Richard. Declínio do Homem Público. São Paulo: Cia. das Letras, 1988. As citações seguintes serão referenciadas no próprio corpo do texto, com a simples indicação da página. 
NADER, Pedro Eduardo Portilbo. A controvérsia sobre a experiência privada na moderniclade.

O Declínio do Homem Público é, assim, perpassado pelo duplo problema da relação entre os domínio público e privado e dos modos de expressão que os acompanham. A sua leitura implica e provoca o problema do que se esconde atrás da aparência dos signos impessoais e pessoais.

No mundo moderno, as relações sociais somente adquirem relevo em função da identidade pessoal. A erosão da esfera pública acarretou não um vazio, mas a invasão do seu espaço pelo que é do âmbito privado.

Esta é uma inclinação forte, predominante, porém, recente, e nem sempre foi assim, observa Sennett. Antes do século XIX, a atuação na instância pública era intensa. No teatro, o público participava ativamente, intervinha na cena, exprimia as sensaçöes durante o próprio ato, enfim, a peça era lugar de expressão de uma sociabilidade. O café era um local de encontros com estranhos e de conversas impessoais. Opostos do teatro e do café modernos, onde se espera a discrição e o desfrutar a sós ou a dois; as praças pré-modernas visavam a permanência e o convívio públicos; as ruas modernas destinam-se ao mevimento e à passagem. Regra básica de conduta no espaço público segundo a civilidade moderna: manter relaçóes que consideram, sobretudo, a distância que a pessoa deve ter com os estranhos.

$O$ indivíduo evita a visibilidade pública, reforçando o desejo de transparência nas relações intimistas. "O silêncio em público se tornou o único pelo qual se poderia experimentar a vida pública, especialmente a vida nas ruas, sem se sentir esmagado" (p. 43).

É preciso observar, o ataque sennettiano procura não o rígido individualismo, tantas vezes bombardeado por estudos anteriores ${ }^{3}$, mas mira muito mais a expectativa do sentimento privado e da personalidade comandando o mundo. "A guerra entre a psique e a sociedade travou-se (...) dentro do próprio indivíduo. Ele perde a capacidade de jogo e de desempenho numa sociedade que não the permite espaço impessoal onde representar" (p. 325).

Rousseau foi o primeiro a acusar a cidade como uma sociedade secular, cujas relações eram falsas como num teatro, comenta Sennett: a crítica rousseauniana observava no cenário urbano cada indivíduo portando uma máscara. $\mathrm{O}$ autor genebrino, que entendia a humanidade como primordial e

3 Da mais nova safra de livros a proposito do tema, ver LASCH, Christopher. A Cultura do Narcisismo. Rio de Janeiro: Imago, 1983. 
naturalmente boa, via na cidade a corrupção dos costumes e na sociabilidade o resultado das falsas relações urbanas. 'Assim sendo, Rousseau percebe a grande cidade como um meio ambiente dentro do qual não se pode dizer que tipo de homem um estranho é (p. 151). Sennett enxerga em Rousseau a propensão ao desequilíbrio do espírito político e à supressão do espaço público: mas estas duas inclinações efetivaram-se precisamente nas grandes cidades, ao contrário do que indicavam as profecias rousseaunianas.

O texto sennetiano respalda-se na contraposição a Rousseau: a capacidade de se relacionar em público de forma impessoal é própria da civilidade e nisto, diz Sennett, não reside nenhuma restrição; antes, é este aspecto que necessitamos ressuscitar urgentemente.

Vou procurar agora examinar os fundamentos de $O$ Declínio do Homem Público, quais os seus preceitos da relação público-privado, qual a fonte em que Sennett vai buscar os parâmetros para refutar a cultura moderna em nome da potencialidade de uma distante natureza pública. Chamo a atenção para o fato de que, apesar de discordar da tese central do livro de Sennett - e é dela que vou tratar aqui -, considero crucial o tema que o autor elabora, acho inspiradora a apresentação do problema e original a própria tese central, avalio o trabalho de fontes muitíssimo bem realizado e minucioso. Para investigar o manuseio historiográfico dos documentos e os hábeis painéis e descrições que o historiador elabora, seria necessária uma outra análise, distinta da pretendida nesta resenha. (De qualquer modo, as duas perspectivas não são excludentes, senão complementares).

Substituição de uma natureza por outra: denegação da "natureza" privada moderna ("o que é autêntico em nossos sentimentos" (p. 16) em troca de afirmação da natureza pública. Aquilo que é tido como "natureza" em outros saberes (teoria psicanalítica, formulação freudiana, etc.), em Sennett é compreendido (e reprovado) como artifício: a cultura intimista não responde às "legítimas" necessidades do ser humano.

Crítico da elaboração rousseauniana, O Declínio do Homem Público preserva o que era em Rousseau a matriz: a impugnação do artifício e o desejo de autenticidade. Mudados e virados os sinais entre o público e o privado, sinais que exigem adequações e retificações, o plano geral da "natureza" humana é mantido.

O espírito público, nesta história, perde-se progressivamente no curso dos acontecimentos: no início era a vocação ao domínio público; em seguida veio o 
NADER, Pedro Eduardo Portilho. A controvérsia sobre a experiência privada na modernidade.

artif́cio intimista que falsificou tudo. A idéia de modificação histórica é aqui aproximada da idéia de falsificação: a instância pública original aviltou-se e perverteu-se, gerando o predomínio da vida privada. Este é "o resultado de um longo processo histórico, um processo em que os próprios termos da natureza humana foram transformados num fenômeno individual, instável e auto-absorvido, que chamamos "personalidade'" (p. 412).

O desprezo pela modernidade marca os parametros de $O$ Declínio do Homem Público: por trás da crítica da forma de modernidade percebida deterioração e falsificação das relaçöes do indivíduo com os outros encontra-se $o$ ideal de uma forma de vivência diversa - a autenticidade de tempos diferentes ${ }^{4}$. Em nenhum momento o livro de Sennett preocupa-se "verdadeiramente" com o seu presente: o seu pensamento é sobretudo um pensamento do passado e do futuro, i.e., do que não existe e que encontra nas noçōes "naturais públicas" um abrigo terminológico. Pensamento do passado: "Essa história é a história da erosão de um equilíbrio delicado que mantinha a sociedade no primeiro jato de sua existência secular e capitalista. Era um equilíbrio entre a vida pública e a vida privada, um equilíbrio entre um terreno impessoal em que os homens poderiam investir uma espécie de paixão e um terreno pessoal em que poderiam investir uma outra espécie" (pp. 412-3). Este modo de vida, observa Sennett, calcava-se então na idéia de uma caráter humano natural que era relevado - e não criado como é modernamente - pelas experiências de uma vida (cf. p. 413). Pensamento do futuro: "A renovação da cidade, a rejeição das cadeias do bairrismo (...) - é também a renovação de um prinć́pio de comportamento político. A extensão em que as pessoas podem aprender a perseguir agressivamente seus interesses em sociedade é a extensão em que elas aprendem a agir de modo impessoal. A cidade deveria ser mestra nesse modo de agir, o forum no qual se torna signicativo unir-se a outras pessoas sem a compulsão de conhecê-las enquanto pessoas" (p. 414), comenta o historiador no encerramento de seu livro.

4 Um aparente paradoxo surge aqui: a autenticidade de tempos diferentes é a máscara social, a polidez no trato social. Falso paradoxo: a polidez é autenticidade, posto que não se confunde com a hipocrisia nas relaçőes socials. A hipocrisia instaura-se como produto do descaso com o que é da alçada póblica, fruto do intimismo moderno. Bem claro, quando SENNETT rejeita a autenticidade (cf. p. 47), ele rejeita o que na modernidade aparece como autêntico, i.e, a sinceridade pessoal, a expressão sentimental do eu. 
Ainda: vendo a essência do público localizada no espaço impessoal das sociedades ocidentais pré-modernas, Sennett tece uma dicotomia inflexível e estilizada entre o "público" e o "privado", entre o "impessoal" e o "pessoal", montando uma rígida relação de exterioridade entre as duas, instâncias. Desta forma, é impossível para o autor deixar de pensar a modernidade em termos do afrontamento entre um domínio e outro. Na narrativa sennettiana, aquilo que era percebido em eqüidade nas sociedades pré-modernas, é apreendido pelo historiador em ruptura e confronto no mundo moderno. Mas, o problema que cabe colocar é: o que é vivido na época moderna é a defrontação do que era vivido anteriormente em equilíbrio, ou trata-se de uma outra experiência, diversa em suas expressões?

Lembremos o exemplo de análise histórica sugerida pelos estudos de Michel Foucault e privilegiada, em algum grau, na leitura de Paul Veyne: a "punição", a "sexualidade", o "governo", não existem; o que existem são objetos que têm atuações flexíveis e que se definem apenas a partir de suas estratégias. Não existem uma forma de punição adequada (em oposição às prisões e institutos penitenciários corrompidos e degradados que conhecemos), uma sexualidade ótima (em distinção seja à sexualidade reprimida da época vitoriana seja à "dessublimação repressiva da sociedade de massas segundo Herbert Marcuse), um governo bom (em contraste ao governo ineficaz e interesseiro), que só por acidente podem cair, alienar-se e ser usados por egoístas e ambiciosos. Não há uma defasagem entre o ser, a essência e a sua manifestação singular. Em outros termos, não é a mesma substancia que percorre, invariante, os caminhos da História. A análise foucaultiana suspende a naturalidade a-histórica com que freqüentemente são utilizadas as "noções tão cotidianas e tão recentes" ${ }^{5}$ de doença mental, criminalidade, sexualidade, Estado; questiona sobre quais campos de constituição e validade foram constituidas tais noções; indaga a respeito de formas de sociedade onde as categorias com que estamos habituados não seriam mais constituintes, mostrando que estas categorias são constituídas - e não constituintes - em nossas práticas.

Retomando o tema do homem público: evitar uma apreciação negativista da modernidade, segundo elementos pré-modernos supostamente invariantes,

5 Estou pluralizando uma expressão extraída de: FOUCAULT, Michel. História da Sexualidade v. 2: $O$ Uso dos Prazeres. Rio de Janeiro: Graal, 1984. 
NADER, Pedro Eduardo Portilho. A controvérsia sobre a experiência privada na modernidade.

mas buscar interpelar o mundo moderno conforme sua positividade instaurada: ao invés de uma exterioridade entre o público e o privado, procurar compreender a modernidade pelas relações intrínsecas firmadas entre o indivíduo e o mundo social que o rodeia, relações que são reguladas de uma maneira ímpar, diferente das regulagens nas sociedades onde predominavam a "comunidade" e a "vida pública". Evitar, em suma, que "comunidade" e "vida pública" sejam tomadas como categorias históricas constantes : as substâncias da "comunidade" e da "vida pública" não são permanentes, as mesmas modernamente e em tempos anteriores, cujas caracterizações atuais seriam negativas, depauperadas de seu significado pleno.

A narrativa sennettiana revela assim seu caráter de intransigência: toda inconveniência e angústia sentidas - no caso, a primazia da intimidade - serão consideradas como artifício - perda - que imputa à natureza pública um constrangimento e uma violência que requerem, por parte do intelectual, denúncia e repúdio. Uma aversâo enérgica implode $O$ Declínio do Homem Público: trata-se, em Sennett, não tanio de admirar e receitar a vivência pública - como aparece claramente numa leitura imediata —, senão, antes e com muito mais importância, de apresentar uma má-vontade vigorosa e rechaçar por completo o mundo moderno baseado nas relações intimistas e personalizadas. Enfim: não se preocupa "de verdade" com o presente, porém intenta em todo o texto depreciá-lo, estimando outras formas e outros tempos de sociedade, de acordo com um modelo categorial estático. A avaliação do domínio público é carregada e acumulada pelas noções de detrimento, perda, negatividade, com que são vistas no mundo moderno. Mais que um sentimentalismo do autor, a matriz naturalista, tomada compulsoriamente por Sennett na sua leitura de Rousseau, exige uma profunda antipatia pelo presente.

A questão não é ter que decidir entre a autenticidade (de matriz rousseauniana) e a civilidade moderna ("incivilizada", nos termos de Sennett) tal opção é a alternativa oferecida pelo historiador das "tiranias da intimidade" na conclusão de sua obra. A pergunta que se faz necessária seria antes: qual o motivo - histórico - da perseverança, tão arraigada e tão incisiva, desta crença na dualidade auténtico-inautêntico?

Reduzir a vivência que as pessoas têm das esferas públicas e privadas a mero desfibramento moderno, que psicologiza o político implica dizer que estas pessoas não "vivem de verdade", não têm uma existência repleta de vida, em comparação com as pessoas que viveram em épocas de plenitude. Antipatia pelo 
R. Histórla, Sáo Paulo, n. 121, p. 165-171, ago/dez. 1989.

presente: numerosos críticos e intelectuais incorreram neste "vício", acentuando o caráter de passividade e submissão que o "seu presente" empresta aos indivíduos de então. O diagnóstico, no entanto, não pode ser assim tão simpies. A modemidade é também diálogo, não, evidentemente, contactos e intercâmbios entre sujeitos no domínio público, mas explorações nas quais o que está em jogo não é somente a adesão silenciosa do indivíduo. 